\title{
Analysis of the Mechanism of Prolonged Persistence of Drug Interaction between Terbinafine and Amitriptyline or Nortriptyline
}

\author{
Akiko Mikami, ${ }^{a}$ Satoko Hori, ${ }^{a, b}$ Hisakazu Ohtani, ${ }^{c}$ and Yasufumi Sawada ${ }^{* a}$ \\ ${ }^{a}$ Graduate School of Pharmaceutical Sciences, The University of Tokyo; 7-3-1 Hongo, Bunkyo-ku, Tokyo 113-0033, \\ Japan: ${ }^{b}$ Interfaculty Initiative in Information Studies, The University of Tokyo; 7-3-1 Hongo, Bunkyo-ku, Tokyo 113- \\ 0033, Japan: and ${ }^{c}$ Faculty of Pharmacy, Keio University; 1-5-30 Shibakouen, Minato-ku, Tokyo 105-8512, Japan. \\ Received December 21, 2016; accepted April 24, 2017
}

The purpose of the study was to quantitatively estimate and predict drug interactions between terbinafine and tricyclic antidepressants (TCAs), amitriptyline or nortriptyline, based on in vitro studies. Inhibition of TCA-metabolizing activity by terbinafine was investigated using human liver microsomes. Based on the unbound $K_{\mathrm{i}}$ values obtained in vitro and reported pharmacokinetic parameters, a pharmacokinetic model of drug interaction was fitted to the reported plasma concentration profiles of TCAs administered concomitantly with terbinafine to obtain the drug-drug interaction parameters. Then, the model was used to predict nortriptyline plasma concentration with concomitant administration of terbinafine and changes of area under the curve $(A U C)$ of nortriptyline after cessation of terbinafine. The CYP2D6 inhibitory potency of terbinafine was unaffected by preincubation, so the inhibition seems to be reversible. Terbinafine competitively inhibited amitriptyline or nortriptyline $E$-10-hydroxylation, with unbound $K_{\mathrm{i}}$ values of 13.7 and $12.4 \mathrm{~nm}$, respectively. Observed plasma concentrations of TCAs administered concomitantly with terbinafine were successfully simulated with the drug interaction model using the in vitro parameters. Model-predicted nortriptyline plasma concentration after concomitant nortriptylene/terbinafine administration for two weeks exceeded the toxic level, and drug interaction was predicted to be prolonged; the $A U C$ of nortriptyline was predicted to be increased by 2.5- or 2.0- and 1.5-fold at 0,3 and 6 months after cessation of terbinafine, respectively. The developed model enables us to quantitatively predict the prolonged drug interaction between terbinafine and TCAs. The model should be helpful for clinical management of terbinafine-CYP2D6 substrate drug interactions, which are difficult to predict due to their time-dependency.

Key words terbinafine; CYP2D6; drug interaction; amitriptyline; nortriptyline

Terbinafine (TER), an antifungal agent, inhibits CYP2D6. It was reported to increase the plasma concentrations of the CYP2D6 substrate drugs imipramine ${ }^{1)}$ and desipramine, ${ }^{2,3)}$ inducing adverse reactions to these drugs. TER also increased the plasma concentration of paroxetine ${ }^{4)}$ and the urinary dextromethorphan/dextrophan ratio., ${ }^{5,6}$ TER interactions are characterized by long persistence; for example, concomitant use of the antipsychotic perphenazine and TER led to appearance of an extrapyramidal symptom (marked akathisia), which persisted for 3 weeks following discontinuation of TER. ${ }^{7)}$

With regard to amitriptyline (AT) and nortriptyline (NT), it has been reported that concomitant administration with TER greatly increased the plasma concentration of AT or NT, inducing adverse drug reactions such as thirst, nausea, and vertigo that persisted for a long time following discontinuation of TER. ${ }^{8-10)}$ AT undergoes demethylation to NT, catalyzed mainly by CYPs other than CYP2D6, but the primary metabolic route for both AT and NT is hydroxylation at the $E-10$ position, ${ }^{11)}$ which is mediated mainly by CYP2D6, but also slightly by CYP3A4. ${ }^{12,13)}$

TER has a very long elimination half-life; in patients who received oral administration of $250 \mathrm{mg} / \mathrm{d}$ for 28 consecutive days, its plasma concentration was $0.2 \mu \mathrm{M}$ at 1 month after the treatment, meaning that the drug had not been eliminated completely after a month. ${ }^{14)}$ In addition, strong competitive inhibition of dextromethorphan $O$-demethylation activity by TER has been observed in vitro. ${ }^{15,16)}$ However, the inhibitory constants of TER for NT and AT remain unknown. Although the long persistence of CYP inhibition could also be explained by irreversibility, CYP inhibition by TER has been shown not to be time-dependent. ${ }^{17)}$ Therefore, the prolonged persistence of TER interactions may be explained by the potent inhibitory activity and extremely slow elimination rate of TER.

To predict the blood concentration profile of a concomitant medication following discontinuation of TER (i.e., to determine how long the interaction persists), proper regimen design is important. It would also be useful to predict the risk of interaction at the dose of TER generally used in Japan, $125 \mathrm{mg} / \mathrm{d}$ (half that used in other countries). ${ }^{18)}$ However, there has been only one study along this line, in which the $A U C$ elevation ratio after a single concomitant dose of TER $250 \mathrm{mg} / \mathrm{d}$ with a CYP2D6 metabolizer was predicted. ${ }^{19)}$ Therefore, to manage clinically significant interactions between TER and CYP2D6 substrate drugs, it is important to develop a model for predicting quantitatively the extent and time dependence of the interactions.

Therefore, the present study was conducted to examine the inhibitory activities and inhibitory modes of TER towards CYP2D6 and CYP3A4 in a human hepatic microsomal system in vitro. We also aimed to develop a model for describing the interactions between TER and AT or NT using the in vitro inhibitory parameters thus obtained, and to use the developed model in order to quantitatively predict the in vivo interactions.

\section{METHODS}

Chemicals Terbinafine hydrochloride (TER), quinidine, 
testosterone, dextromethorphan hydrobromide monohydrate, amitriptyline hydrobromide (AT), dextrorphan-D-tartrate, paroxetine hydrochloride, and magnesium chloride hexahydrate were purchased from Wako Pure Chemical Industries, Ltd. (Osaka, Japan). Nortriptyline hydrochloride (NT), ( \pm )-E10-hydroxynortriptyline maleate salt, ( \pm )-E-10-hydroxyamitriptyline maleate salt, desipramine hydrochloride, levallorphan tartrate salt, and itraconazole were purchased from Sigma (St. Louis, MO, U.S.A.). Glucose-6-phosphate dehydrogenase and D-glucose-6-phosphate disodium salt were purchased from Oriental Yeast Co. (Tokyo, Japan). Pooled human liver microsomes were purchased from GENTEST Corporation (Woburn, MA, U.S.A.). Other chemicals were of HPLC grade or the highest grade commercially available.

Inhibition Assays for CYP2D6 and CYP3A4 Activity in Human Liver Microsomes The activity of CYP2D6 or CYP3A4 was assayed by measuring the formation of dextrorphan from dextromethorphan or the formation of $6 \beta$-hydroxytestosterone from testosterone in human liver microsomes, respectively. The incubation mixture contained $50 \mathrm{~mm}$ sodium phosphate buffer ( $\mathrm{pH} 7.4)$, a reduced nicotinamide adenine dinucleotide phosphate (NADPH)-generating system (1 mM NADPH, $5 \mathrm{~mm}$ glucose-6-phosphate, 1 unit/mL glucose-6-phosphate dehydrogenase, $3 \mathrm{~mm} \mathrm{MgCl}_{2}$ ), and human liver microsomes $(0.125 \mathrm{mg} / \mathrm{mL}$ in dextromethorphan assay, $0.1 \mathrm{mg} / \mathrm{mL}$ in testosterone assay). Total volume was $200 \mu \mathrm{L}$ in dextromethorphan assay, and $500 \mu \mathrm{L}$ in testosterone assay. Microsomal incubations were carried out at $37^{\circ} \mathrm{C}$ in a shaking incubator. The reactions were initiated by the addition of inhibitors (itraconazole $0,1,5 \mu \mathrm{M}$ or quinidine $0.5 \mu \mathrm{M}$ in dextromethorphan assay, itraconazole $0.1,5 \mu \mathrm{M}$ or TER 1, 2, $5,10 \mu \mathrm{m}$ in testosterone assay) and substrates (10 $\mu \mathrm{M}$ dextromethorphan or $50 \mu \mathrm{M}$ testosterone) and subsequently terminated after $20 \mathrm{~min}$ by the addition of $200 \mu \mathrm{L}$ cold methanol containing $1.25 \mu \mathrm{M}$ internal standard levallorphan (in dextromethorphan assay) or $5 \mathrm{~mL}$ dichloromethane (in testosterone assay). The mixtures were used for the determination of dextrorphan or $6 \beta$-hydroxytestosterone.

To assess the effect of preincubation on the inhibitory potency for CYP2D6, the reaction mixture consisting of the NADPH-generating system, human liver microsomes, and TER $(0,0.02,0.05,0.1,0.2,0.5,1 \mu \mathrm{M})$ or paroxetine $(0,0.2$, $0.5,1,2,5 \mu \mathrm{M})$ or quinidine $(0,0.02,0.05,0.1,0.2,0.5,1 \mu \mathrm{M})$ was preincubated for 0 or $10 \mathrm{~min}$ at $37^{\circ} \mathrm{C}$. The reaction was initiated by adding $10 \mu \mathrm{M}$ dextromethorphan and terminated after $20 \mathrm{~min}$ by the addition of $200 \mu \mathrm{L}$ cold methanol containing $1.25 \mu \mathrm{M}$ internal standard levallorphan. The mixtures were used for the determination of dextrorphan.

A control study to determine the kinetics of dextrorphan formation from dextromethorphan was performed as described above except that dextromethorphan concentration was 1, 2, 5, 10 , or $20 \mu \mathrm{M}$ and inhibitors were absent.

In dextromethorphan assay, the following equation was fitted to the observed data in the control study (mean of $n=3$ ) using a nonlinear iterative least-squares method (MLAB, Civilized Software Inc., Bethesda, MD, U.S.A.) to obtain kinetic parameters for the metabolism of dextromethorphan.

$$
v=\frac{V_{\max } \cdot S}{K_{\mathrm{m}}+S}
$$

where $v, V_{\max }, K_{\mathrm{m}}$, and $S$ represent the metabolic reaction velocity, maximum metabolic reaction velocity, MichaelisMenten constant, and the concentration of dextromethorphan, respectively.

Using these kinetic parameters, the following equation was fitted to the observed data in the preincubation-dependent inhibition study (mean of $n=3$ ) to obtain $K_{\mathrm{i}}$, the inhibitory constant for dextromethorphan $O$-demethylation by each inhibitor, with or without preincubation.

$$
v=\frac{V_{\max } \cdot S}{K_{\mathrm{m}} \cdot\left(1+\frac{I}{K_{\mathrm{i}}}\right)+S}
$$

Assays for $E$-10-Hydroxylation of AT and NT in Human Liver Microsomes The activity of $E$-10-hydroxylation was assayed by measuring the formation of $E$-10-hydroxyamitriptyline from AT or E-10-hydroxynortriptyline from NT in human liver microsomes, respectively. The incubation mixture contained $50 \mathrm{~mm}$ sodium phosphate buffer $(\mathrm{pH} 7.4)$, an NADPH-generating system, and human liver microsomes $(0.125 \mathrm{mg} / \mathrm{mL})$. Total volume was $200 \mu \mathrm{L}$ in AT assay, and $400 \mu \mathrm{L}$ in NT assay. Microsomal incubations were carried out in $37^{\circ} \mathrm{C}$ in a shaking incubator. The reactions were initiated by the addition of inhibitor (itraconazole $1 \mu \mathrm{M}$ or quinidine $5 \mu \mathrm{M}$ or no inhibitor) and AT or NT (with inhibitors: $2,5,10$, 20, 50, $100 \mu \mathrm{M}$, without inhibitors: $0.2,0.5,1,2,5,10,20$, $50,100 \mu \mathrm{M})$ and terminated after $20 \mathrm{~min}$ by the addition of an equal volume of cold methanol containing $1.25 \mu \mathrm{M}$ internal standard desipramine. The mixtures were used for the determination of $E$-10-hydroxylated AT or NT.

To investigate the inhibition of $E$-10-hydroxylation by TER, TER $(0,0.1,0.5 \mu \mathrm{M})$ and AT or NT $(2,5,10,20,50 \mu \mathrm{M})$ were used. Assays were performed as described above.

To investigate the concentration-dependent inhibitory potency of TER for $E$-10-hydroxylation, TER (0, 0.02, 0.05, 0.1, $0.2,0.5,1,2,5 \mu \mathrm{M})$ and AT or NT $(2 \mu \mathrm{M})$ were used. Assays were performed as described above, in the presence or absence of $1 \mu \mathrm{M}$ itraconazole. Itraconazole was added with TER.

The following Eqs. 3 to 5 were simultaneously fitted to the observed data (mean of $n=3$ ) from experiments without inhibitor, or with itraconazole, or with quinidine, respectively, to obtain kinetic parameters for the $E$-10-hydroxylation of AT and NT.

$$
\begin{aligned}
& v=\frac{V_{\max 1} \cdot S}{K_{\mathrm{m} 1}+S}+\frac{V_{\max 2} \cdot S}{K_{\mathrm{m} 2}+S} \\
& v=\frac{V_{\max 1} \cdot S}{K_{\mathrm{m} 1}+S} \\
& v=\frac{V_{\max 2} \cdot S}{K_{\mathrm{m} 2}+S}
\end{aligned}
$$

where $v, V_{\max }, K_{\mathrm{m}}$, and $S$ represent the metabolic reaction velocity, maximum metabolic reaction velocity, MichaelisMenten constant, and concentration of AT or NT, respectively. These parameters are common in the equations.

Using these kinetic parameters, the following Eqs. 6 and 7 were simultaneously fitted to the observed data from the TER concentration-dependent inhibition study (mean of $n=3$ ) from experiments in the absence and presence of itraconazole, respectively, to obtain $K_{\mathrm{i}}$, the inhibitory constant for $E$-10-hydroxylation of AT or NT by TER. 


$$
\begin{aligned}
& v_{1}=\frac{V_{\max 1} \cdot S}{K_{\mathrm{m} 1} \cdot\left(1+\frac{I}{K_{\mathrm{i}}}\right)+S}+\frac{V_{\max 2} \cdot S}{K_{\mathrm{m} 2}+S} \\
& v_{2}=\frac{V_{\max 1} \cdot S}{K_{\mathrm{m} 1} \cdot\left(1+\frac{I}{K_{\mathrm{i}}}\right)+S}
\end{aligned}
$$

Measurement of Nonspecific Binding of TER to Human Liver Microsomes and Estimation of Unbound Inhibitory Constant of TER Nonspecific binding of TER to human liver microsomes was determined by equilibrium dialysis using an equilibrium dialyzer with Teflon dialysis cells of $0.5 \mathrm{~mL}$ capacity per side and Spectrapor dialysis membrane (molecular weight cut off 12000-14000 Da) purchased from Spectrum Laboratories Inc. (Rancho Dominguez, CA, U.S.A.). TER $(0.05,0.2,2,10 \mu \mathrm{M})$ and $0.125 \mathrm{mg} / \mathrm{mL}$ human liver microsomes in $50 \mathrm{~mm}$ sodium phosphate buffer ( $\mathrm{pH} 7.4)$ was applied to one cell, and $50 \mathrm{~mm}$ sodium phosphate buffer to the other. The sample volume was $0.5 \mathrm{~mL}$. After incubation at $37^{\circ} \mathrm{C}$ for $5 \mathrm{~h}, 0.4 \mathrm{~mL}$ of the sample was collected from both cells for determination of TER. As a control, without human liver microsomes, assays were performed as described above.

TER recovery from each sample was calculated according to the following equation:

$$
R=\frac{C_{\mathrm{b}}+C_{\mathrm{m}}}{C_{0}}
$$

where $C_{\mathrm{m}}, C_{\mathrm{b}}, C_{0}$ represent the TER concentration in the addition side, buffer side, and initial solution, respectively.

The unbound fraction of TER to human liver microsomes was calculated according to the following equation:

$$
f=\frac{C_{\mathrm{b}}}{C_{\mathrm{m}}}
$$

The linear correlation of TER concentration and TER unbound fraction was calculated from TER unbound concentration in the TER concentration-dependent inhibition assay, and used to estimate the unbound inhibitory constant of TER from the observed data, as described above.

HPLC Analysis HPLC analyses were performed using an LC-10AD pump (Shimadzu, Kyoto, Japan), SPD-10AV UV detector (Shimadzu) and a COSMOSIL 5C18-MS-II $(4.6 \times 150 \mathrm{~mm}, 5 \mu \mathrm{m})$ column (Nacalai Tesque, Kyoto, Japan).

Quantification of Dextrorphan Proteins were sedimented by centrifugation at $2000 \times \boldsymbol{g}$ for $10 \mathrm{~min}$ at $4^{\circ} \mathrm{C}$, and aliquots of the supernatant $(360 \mu \mathrm{L})$ were mixed with $90 \mu \mathrm{L} 0.5 \mathrm{M}$ sodium carbonate and $5 \mathrm{~mL}$ chloroform. Each mixture was shaken for $10 \mathrm{~min}$ and then centrifuged at $2000 \times \boldsymbol{g}$ for $10 \mathrm{~min}$. The organic phase was evaporated to dryness and the residue was redissolved in $100 \mu \mathrm{L}$ mobile phase. The mobile phase consisted of $0.01 \mathrm{M}$ phosphate buffer ( $\mathrm{pH} 2.9$ ) and acetonitrile $(80: 20, \mathrm{v} / \mathrm{v})$, and was pumped at a flow rate of $1.0 \mathrm{~mL} / \mathrm{min}$. The detection wavelength was set at $280 \mathrm{~nm}$. The quantification range was $0.020-5 \mu \mathrm{M}$.

Quantification of 6 $\boldsymbol{\beta}$-Hydroxytestosterone Each mixture was centrifuged at $2000 \times \boldsymbol{g}$ for $10 \mathrm{~min}$. The organic phase was evaporated to dryness and the residue was redissolved in $100 \mu \mathrm{L}$ mobile phase. An $80 \mu \mathrm{L}$ aliquot was subjected to HPLC. The mobile phase consisted of $58 \%$ methanol $(\mathrm{v} / \mathrm{v})$ and was pumped at a flow rate of $1.0 \mathrm{~mL} / \mathrm{min}$. The detection wavelength was set at $242 \mathrm{~nm}$. The quantification range was $0.010-100 \mu \mathrm{M}$.

Quantification of $\boldsymbol{E}-\mathbf{1 0}$-Hydroxylated AT or NT Protein was sedimented by centrifugation at $2000 \times \boldsymbol{g}$ for $10 \mathrm{~min}$ at $4^{\circ} \mathrm{C}$, and aliquots of the supernatant (AT: $360 \mu \mathrm{L}, \mathrm{NT}: 720 \mu \mathrm{L}$ ) were mixed with a $1 / 4$ volume of $0.5 \mathrm{M}$ sodium carbonate and $5 \mathrm{~mL}$ chloroform. Each mixture was shaken for $10 \mathrm{~min}$ and centrifuged at $2000 \times \boldsymbol{g}$ for $10 \mathrm{~min}$. The organic phase was evaporated to dryness and the residue was redissolved in $100 \mu \mathrm{L}$ mobile phase. An $80 \mu \mathrm{L}$ aliquot was subjected to HPLC. The mobile phase consisted of $0.01 \mathrm{~m}$ phosphate buffer $(\mathrm{pH} 2.5)$ and acetonitrile $(75: 25, \mathrm{v} / \mathrm{v})$ and was pumped at a flow rate of $1.0 \mathrm{~mL} / \mathrm{min}$. The detection wavelength was set at $240 \mathrm{~nm}$. The quantification range of each drug was $0.005-10 \mu \mathrm{M}$.

Quantification of TER An equal volume of $0.06 \mathrm{M}$ hydrochloric acid was added to samples. The samples containing human liver microsomes were centrifuged at $2000 \times \boldsymbol{g}$ for $10 \mathrm{~min}$. An $80 \mu \mathrm{L}$ aliquot of the supernatant was subjected to HPLC. The mobile phase consisted of $0.01 \mathrm{~m}$ phosphate buffer $(\mathrm{pH} 2.5)$ and acetonitrile $(60: 40, \mathrm{v} / \mathrm{v})$ and was pumped at a flow rate of $1.0 \mathrm{~mL} / \mathrm{min}$. The detection wavelength was set at $224 \mathrm{~nm}$. The quantification range was $0.001-10 \mu \mathrm{M}$.

Determination of Single-Dose Kinetic Parameters It is assumed that AT and NT are eliminated only by the liver ${ }^{20,21)}$ and are completely absorbed. ${ }^{22}$ The reported plasma concentrations after oral single administration of AT or NT to humans ${ }^{23,24)}$ were fitted to a one-compartment model with first-order absorption (Eq. 10) and pharmacokinetic parameters of AT or NT were calculated according to the following Eqs. 11, 12.

$$
\begin{aligned}
C(t) & =\frac{F \cdot \text { Dose } \cdot k_{\mathrm{a}}}{V \cdot\left(k_{\mathrm{a}}-k_{\mathrm{e}}\right)} \cdot\left\{\exp \left(-k_{\mathrm{e}} \cdot t\right)-\exp \left(-k_{\mathrm{a}} \cdot t\right)\right\} \\
F & =\frac{Q h}{f_{\mathrm{u}} \cdot C L_{\text {int }}+Q h} \\
f_{\mathrm{u}} \cdot C L_{\text {int }} & =k_{\mathrm{e}} \cdot \frac{V}{F}
\end{aligned}
$$

where $F, V, k_{\mathrm{a}}, k_{\mathrm{e}}, Q h, f_{\mathrm{u}}, C L_{\text {int }}$ represent bioavailability, distribution volume, absorption rate constant, elimination rate constant, hepatic blood flow, unbound fraction in plasma, and hepatic intrinsic clearance, respectively. $Q h$ is $90 \mathrm{~L} / \mathrm{h}$ based on the previous report. ${ }^{25)}$ The equations assume a well-stirred model.

The reported plasma concentrations after oral single administration of TER to humans ${ }^{26)}$ were fitted to a two-compartment model with first-order absorption (Eq. 13) to calculate the pharmacokinetic parameters of TER.

$$
\begin{aligned}
C(t)= & \frac{F_{\mathrm{t}} \cdot \text { Dose }_{\mathrm{t}} \cdot k_{\mathrm{a}, \mathrm{t}}}{V_{\mathrm{t}}} \cdot\left\{(-A-B) \cdot \exp \left(-k_{\mathrm{a}, \mathrm{t}} \cdot t\right)\right. \\
& +A \cdot \exp (-\alpha \cdot t)+B \cdot \exp (-\beta \cdot t)\} \\
A= & \frac{\left(k_{21}-\alpha\right)}{\left(k_{\mathrm{a}, \mathrm{t}}-\alpha\right) \cdot(\beta-\alpha)}, \quad B=\frac{\left(k_{21}-\beta\right)}{\left(k_{\mathrm{a}, \mathrm{t}}-\beta\right) \cdot(\alpha-\beta)}
\end{aligned}
$$

where $k_{\mathrm{a}, \mathrm{t}}, V_{\mathrm{t}} / F_{\mathrm{t}}, \alpha, \beta, k_{21}$ represent absorption rate constant, apparent distribution volume of the central compartment, $\alpha$-phase elimination rate constant, $\beta$-phase elimination rate 
constant, and equilibrium constant between the central and peripheral compartments, respectively.

Determination of Multiple-Dose Pharmacokinetic Parameters of TER After repeated administration for 4 weeks, TER accumulated approximately twofold and exhibited a triphasic decline, with a very long terminal disposition halflife of $16.5 \mathrm{~d}^{14)}$ Therefore, the reported plasma concentrations after oral repeated administration of TER to humans ${ }^{14)}$ were fitted to a three-compartment model with first-order absorption (Eq. 14) to calculate multiple-dose pharmacokinetic parameters of TER.

$$
\begin{aligned}
C(t)= & \frac{F_{\mathrm{t}} \cdot \text { Dose }_{\mathrm{t}} \cdot k_{\mathrm{a}, \mathrm{t}}}{V_{\mathrm{t}}} \cdot\left\{(-X-Y-Z) \cdot \frac{1-\exp \left(-n \cdot \tau \cdot k_{\mathrm{a}, \mathrm{t}}\right)}{1-\exp \left(-\tau \cdot k_{\mathrm{a}, \mathrm{t}}\right)}\right. \\
& \quad \times \exp \left(-k_{\mathrm{a}, \mathrm{t}} \cdot t\right)+X \cdot \frac{1-\exp (-n \cdot \tau \cdot \alpha)}{1-\exp (-\tau \cdot \alpha)} \cdot \exp (-\alpha \cdot t) \\
& +Y \cdot \frac{1-\exp (-n \cdot \tau \cdot \beta)}{1-\exp (-\tau \cdot \beta)} \cdot \exp (-\beta \cdot t) \\
& \left.+Z \cdot \frac{1-\exp (-n \cdot \tau \cdot \gamma)}{1-\exp (-\tau \cdot \gamma)} \cdot \exp (-\gamma \cdot t)\right\} \\
X= & \frac{\left(k_{21}-\alpha\right) \cdot\left(k_{31}-\alpha\right)}{\left(k_{\mathrm{a}, \mathrm{t}}-\alpha\right) \cdot(\beta-\alpha) \cdot(\gamma-\alpha)} \\
Y= & \frac{\left(k_{21}-\beta\right) \cdot\left(k_{31}-\beta\right)}{\left(k_{\mathrm{a}, \mathrm{t}}-\beta\right) \cdot(\alpha-\beta) \cdot(\gamma-\beta)} \\
Z= & \frac{\left(k_{21}-\gamma\right) \cdot\left(k_{31}-\gamma\right)}{\left(k_{\mathrm{a}, \mathrm{t}}-\gamma\right) \cdot(\alpha-\gamma) \cdot(\beta-\gamma)}
\end{aligned}
$$

where $k_{\mathrm{a}, \mathrm{t}}, V_{\mathrm{t}} / F_{\mathrm{t}}, \alpha, \beta, \gamma, k_{21}, k_{31}$ represent absorption rate constant, apparent distribution volume of the central compartment, $\alpha$-phase elimination rate constant, $\beta$-phase elimination rate constant, $\gamma$-phase elimination rate constant, and equilibrium constant between the central and peripheral compartments, respectively.

Development of Drug-Drug Interaction Model The interaction between AT, NT and TER was modeled based on the following assumptions (Fig. 1). TER is assumed to reversibly inhibit the dispositions of AT and NT, and the unbound inhibitory constants obtained from the in vitro experiments described above were used as TER inhibitory constants for AT $\left(K_{\mathrm{i}_{\mathrm{a}}}\right)$ and NT $\left(K_{\mathrm{i}_{\mathrm{n}}}\right)$. It was assumed that TER, AT, and NT are administered with a zero-order rate constant to simplify the calculation. It was also assumed that the elimination rate constants of AT and NT are different between each case report to consider the variability in metoprolol metabolism. In the metabolic pathways of AT and NT, it was assumed that CYP2D6 contributes only to $E$-10-hydroxylation, and except for $E$-10-hydroxylation, AT is completely $N$-demethylated to NT, because the CYP2D6 contribution to $N$-demethylation and the CYP3A4 contribution to E-10-hydroxylation are both negligible in AT metabolism. ${ }^{13)}$ Furthermore, concentrative uptake of TER into the liver was considered, and it was assumed that the distribution of TER in the liver rapidly reaches equilibrium.

The mass balance equations for plasma concentration of AT and NT are given as follows:

$$
\frac{\mathrm{d} C_{\mathrm{a}}}{\mathrm{d} t}=\frac{F \cdot \text { Dose } / \pi}{V_{\mathrm{a}}}-k_{\mathrm{e}, \mathrm{a}} \cdot\left\{\left(1-r_{\mathrm{a}}\right)+\frac{r_{\mathrm{a}}}{1+\frac{K_{\mathrm{P}} \cdot f_{\mathrm{u}} \cdot C_{\mathrm{t} 1}}{K_{\mathrm{i}_{\mathrm{a}}}}}\right\} \cdot C_{\mathrm{a}}
$$

\section{AT (a)}

NT (n)

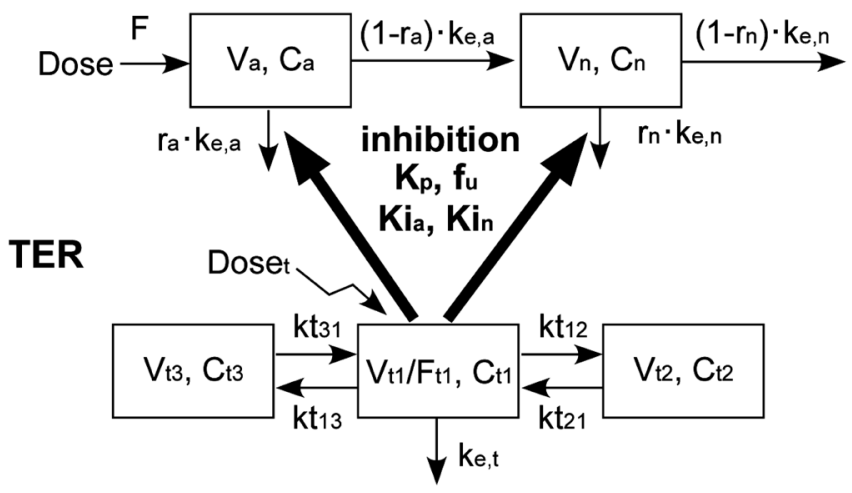

Fig. 1. Pharmacokinetic Model to Describe the Interaction between TER and AT or NT

Dose: Dosage of AT or NT $(\mu \mathrm{g})$; F: bioavailability of AT or NT; $V_{\mathrm{a}}$ : AT distribution volume $(\mathrm{L}) ; C_{\mathrm{a}}$ : AT plasma concentration $(\mathrm{ng} / \mathrm{mL}) ; r_{\mathrm{a}}$ : fractional contribution of CYP2D6 to overall clearance of AT; $k_{\text {en }}$ : AT elimination rate constant $(/ \mathrm{h}) ; V_{\mathrm{n}}$ : NT distribution volume $(\mathrm{L}) ; C_{\mathrm{n}}$ : NT plasma concentration $(\mathrm{ng} / \mathrm{mL}) ; r_{\mathrm{n}}$ : fractional contribution of CYP2D6 to overall clearance of NT; $k_{\mathrm{e}, \mathrm{n}}$ : NT elimination rate constant $(/ \mathrm{h})$; Dose $\mathrm{t}$ : TER dosage $(\mathrm{mg}) ; V_{\mathrm{t} 1} / F_{\mathrm{tt}}$ : TER apparent distribution volume of central compartment (L); $C_{\mathrm{t} 1}$ : TER plasma concentration $(\mu \mathrm{g} / \mathrm{mL}) ; k_{\mathrm{e},}$ TER elimination rate constant $(/ \mathrm{h}) ; k t_{12}, k t_{21}, k t_{13}, k t_{31}$ : TER equilibrium constant between central and peripheral compartment $(/ \mathrm{h}) ; V_{\mathrm{t} 2}, V_{\mathrm{t}}$ : TER distribution volume of peripheral compartment (L); $V_{\mathrm{t}}, V_{\mathrm{t} 3}$ : TER concentration in peripheral compartment $(\mu \mathrm{g} / \mathrm{mL}) ; K_{\mathrm{i}_{\mathrm{a}}}$ : TER inhibitory constant to AT $(\mu \mathrm{g} / \mathrm{mL}) ; K_{\mathrm{i}_{\mathrm{n}}}$ : TER inhibitory constant to NT $(\mu \mathrm{g} / \mathrm{mL}) ; K_{\mathrm{p}}$ : TER liver-to-plasma unbound concentration ratio; $f_{\mathrm{u}}$ : TER unbound fraction in plasma.

$$
\begin{aligned}
\frac{\mathrm{d} C_{\mathrm{n}}}{\mathrm{d} t}= & \frac{C_{\mathrm{a}} \cdot V_{\mathrm{a}} \cdot k_{\mathrm{e}, \mathrm{a}} \cdot\left(1-r_{\mathrm{a}}\right)}{V_{\mathrm{n}}} \\
& -k_{\mathrm{e}, \mathrm{n}} \cdot\left\{\left(1-r_{\mathrm{n}}\right)+\frac{r_{\mathrm{n}}}{1+\frac{K_{\mathrm{P}} \cdot f_{\mathrm{u}} \cdot C_{\mathrm{t} 1}}{K_{\mathrm{i}_{\mathrm{n}}}}}\right\} \cdot C_{\mathrm{n}}
\end{aligned}
$$

where $\tau, r, K_{\mathrm{P}}, f_{\mathrm{u}}, C_{\mathrm{t} 1}, K_{\mathrm{i}}$ represent AT dosage time lag (24h), TER liver-to-plasma unbound concentration ratio, TER unbound fraction in plasma, TER plasma concentration, and TER inhibitory constant, respectively. The value of $f_{\mathrm{u}}$ was taken as $0.004{ }^{18)}$

Plasma concentrations of TER during and after repeated administration were calculated from Eqs. 17, 18, respectively.

$$
\begin{aligned}
C_{\mathrm{t} 1}(t)= & \frac{F_{\mathrm{t}} \cdot \text { Dose }_{\mathrm{t}} / \tau}{V_{\mathrm{t} 1}} \cdot\left[\frac{\left(k_{21}-\alpha\right) \cdot\left(k_{31}-\alpha\right)}{\alpha \cdot(\alpha-\beta) \cdot(\alpha-\gamma)} \cdot\{1-\exp (-\alpha \cdot t)\}\right. \\
& +\frac{\left(k_{21}-\beta\right) \cdot\left(k_{31}-\beta\right)}{\beta \cdot(\beta-\alpha) \cdot(\beta-\gamma)} \cdot\{1-\exp (-\beta \cdot t)\} \\
& \left.+\frac{\left(k_{21}-\gamma\right) \cdot\left(k_{31}-\gamma\right)}{\gamma \cdot(\gamma-\alpha) \cdot(\gamma-\beta)} \cdot\{1-\exp (-\gamma \cdot t)\}\right] \\
C_{\mathrm{t} 1}(t) & =\frac{F_{\mathrm{t}} \cdot \operatorname{Dose} / \tau}{V_{\mathrm{t} 1}} \cdot\left[\frac{\{1-\exp (-\alpha \cdot T)\} \cdot\left(k_{21}-\alpha\right) \cdot\left(k_{31}-\alpha\right)}{\alpha \cdot(\alpha-\beta) \cdot(\alpha-\gamma)}\right. \\
& \times \exp (-\alpha \cdot t)+\frac{\{1-\exp (-\beta \cdot T)\} \cdot\left(k_{21}-\beta\right) \cdot\left(k_{31}-\beta\right)}{\beta \cdot(\beta-\alpha) \cdot(\beta-\gamma)} \\
& \left.\times \exp (-\beta \cdot t)+\frac{\{1-\exp (-\gamma \cdot T)\} \cdot\left(k_{21}-\gamma\right) \cdot\left(k_{31}-\gamma\right)}{\gamma \cdot(\gamma-\alpha) \cdot(\gamma-\beta)} \cdot \exp (-\gamma \cdot t)\right]
\end{aligned}
$$

where $T$ represents the administration term of TER. 
In the case report on administration of AT and TER, the elimination rate constants of AT and NT were calculated based on the following equations and were fixed in the analysis of that report only.

$$
\begin{aligned}
C_{\mathrm{a}, \mathrm{ss}} & =\frac{F \cdot \text { Dose } / \tau}{V_{\mathrm{a}} \cdot k_{\mathrm{e}, \mathrm{a}}} \\
C_{\mathrm{n}, \mathrm{ss}} & =\frac{F \cdot \text { Dose } / \tau \cdot\left(1-r_{\mathrm{a}}\right)}{V_{\mathrm{n}} \cdot k_{\mathrm{e}, \mathrm{n}}}
\end{aligned}
$$

where $C_{\mathrm{a}, \mathrm{ss}}$ and $C_{\mathrm{n}, \mathrm{ss}}$ represent the observed plasma concentrations of AT and NT, respectively, at the steady state before the start of concomitant use with TER in each case.

Model Analysis Case reports ${ }^{8-10)}$ of the interaction that describe the time profiles of the plasma concentrations of AT or NT concomitantly used with TER were collected and used for model analysis.

Equations 15, 16 were simultaneously fitted to the time profiles of the plasma concentrations of AT and NT in the case of administration of AT and TER (case $\mathrm{A}^{8)}$ ), taking the plasma concentration of TER calculated based on the Eqs. 17, 18 and the pharmacokinetic parameters of AT and NT as input functions to obtain common pharmacokinetic parameters, $K_{\mathrm{P}}$, $r_{\mathrm{a}}, r_{\mathrm{n}}$. Then, $K_{\mathrm{P}}, r_{\mathrm{n}}$ were fixed and used for the analysis of the case reports of administration of NT and TER. The drug interaction model shown in Fig. 1 describes the drug interaction of NT and TER when $k_{\mathrm{e}, \mathrm{a}}$ is 1 and $r_{\mathrm{a}}$ is 0 in the Eq. 15, and dosage and bioavailability of AT are substituted for those of NT. Equation 16 was simultaneously fitted to the time profiles of the plasma concentration of NT for the case of the administration of NT and TER (cases $\mathrm{B}^{9)}$ and case $\mathrm{C}^{10)}$ ) to obtain an individual parameter for each case, $k_{\mathrm{e}, \mathrm{n}}$.

Prediction of NT Plasma Concentration after Administration of NT with TER at the Recommended Dose in Japan Using the pharmacokinetic model and parameters, the plasma concentration of NT concomitantly administered with TER was simulated. The dosing schedule was assumed to be as follows: NT $75 \mathrm{mg} / \mathrm{d}$ is concomitantly used with TER $125 \mathrm{mg} / \mathrm{d}$ (the therapeutic dose recommended in Japan) for 2 weeks, and then TER is stopped and the NT dosage is varied from 0 to $75 \mathrm{mg} / \mathrm{d}$.

Prediction of the Duration of TER/NT Interaction Using the pharmacokinetic model and parameters, the $A U C$ of NT when NT is started after cessation of TER administration was simulated. Terbinafine dosage was set at $125 \mathrm{mg} / \mathrm{d}$ or $250 \mathrm{mg} / \mathrm{d}$, and dosing period was the time required to reach the steady-state of TER pharmacokinetics or 2 weeks.

Statistical Analysis Statistical significance of differences was determined with Student's $t$-test, and a $p$ value of less than 0.05 was considered significant.

\section{RESULTS}

Effect of Itraconazole on CYP2D6 Activity, and Effects of Itraconazole and TER on CYP3A4 Activity CYP2D6 activity, determined as dextromethorphan $O$-demethylation activity, was not inhibited by 1 or $5 \mu \mathrm{M}$ itraconazole, while quinidine, used as a positive control, was inhibitory (data not shown). CYP3A4 activity, determined as testosterone $6 \beta$-hydroxylation activity, was potently inhibited by 1 or $5 \mu \mathrm{M}$ itraconazole, while it was not inhibited by $1-10 \mu \mathrm{M}$ TER (data not shown).

Effect of Preincubation on Inhibition of CYP2D6 Activity by TER The values of $V_{\max }$ and $K_{\mathrm{m}}$ for dextromethorphan $O$-demethylation were $135.2 \pm 4.4 \mathrm{pmol} / \mathrm{min} / \mathrm{mg}$ protein and $5.32 \pm 0.92 \mu \mathrm{M}$, respectively. The inhibitory potency of quinidine, used as a negative control, was not affected by preincubation, while the inhibitory potency of paroxetine, used as a positive control, was significantly increased (Fig. 2, Table 1). Terbinafine inhibited dextromethorphan $O$-demethylation, but, as in the case of quinidine, the inhibitory potency was not affected by preincubation. Moreover, the inhibitory constants, $K_{\mathrm{i}}$, of TER for dextromethorphan $O$-demethylation were $0.0389 \mu \mathrm{M}$ with preincubation and $0.0404 \mu \mathrm{M}$ without preincubation, which are not significantly different. These $K_{\mathrm{i}}$ values are consistent with the reported values of $0.028-0.044 \mu \mathrm{M} .{ }^{16)}$

$\boldsymbol{E}$-10-Hydroxylation Kinetics of AT and NT in Human Liver Microsomes For both AT and NT, the E-10-hydrox-
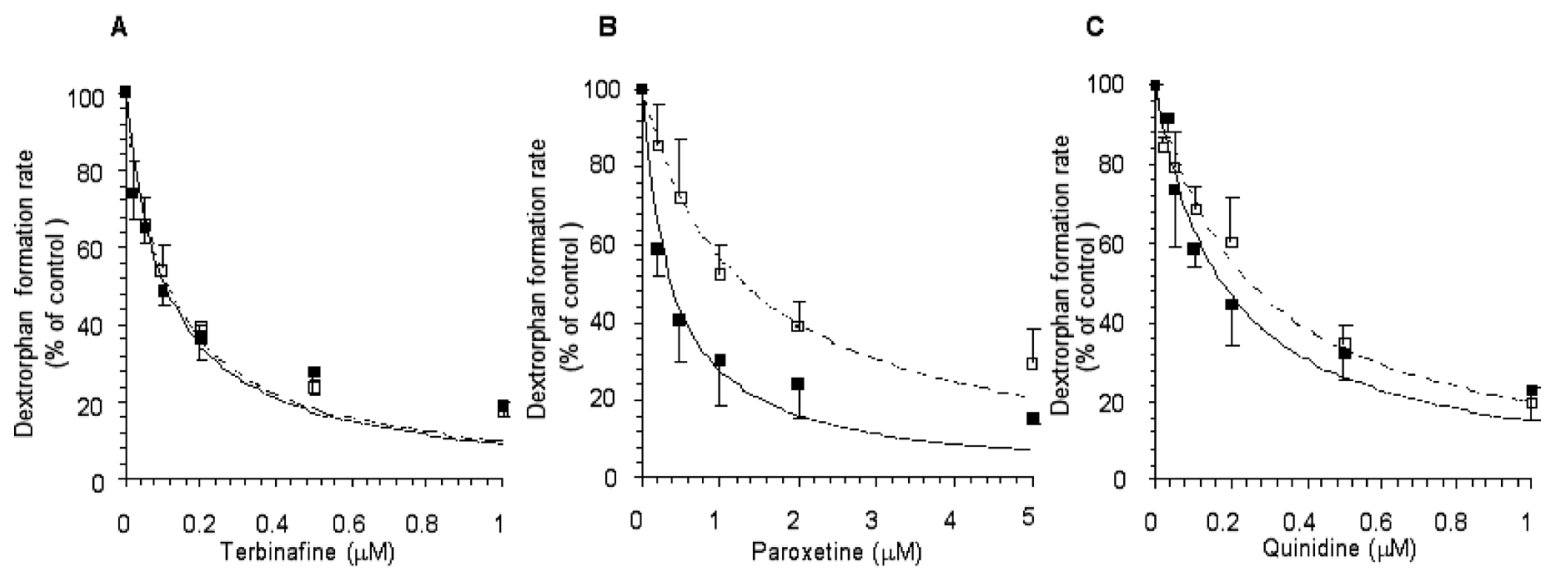

Fig. 2. Effect of Preincubation on Inhibition of Dextromethorphan $O$-Demethylation by TER, Paroxetine or Quinidine in Human Liver Microsomes in Vitro

A: TER, B: paroxetine, C: quinidine. Paroxetine and quinidine were used as positive and negative controls, respectively. Dextrorphan formation rates in the presence of inhibitors are expressed as percentages of that in the absence of inhibitor $(84.0 \pm 7.2 \mathrm{pmol} / \mathrm{min} / \mathrm{mg}$ protein). Each point represents the mean \pm S.E. $(n=3)$. Closed squares and open squares represent data from experiments performed with or without preincubation, respectively. Solid lines and dashed lines are calculated curves of data from experiments performed with or without preincubation, respectively, based on Eq. 2. Initial concentration of dextromethorphan was $10 \mu \mathrm{M}$, preincubation time was 10 min, and incubation time was $20 \mathrm{~min}$. 
ylation kinetics in human liver microsomes were biphasic in the absence of inhibitors, and monophasic in the presence of $1 \mu \mathrm{M}$ itraconazole or $5 \mu \mathrm{M}$ quinidine (Fig. 3). The kinetic parameters are listed in Table 2. E-10-Hydroxylation kinetics were adequately described by assuming that $V_{\max }$ and $K_{\mathrm{m}}$ values in the presence of itraconazole or quinidine correspond to those of the high-affinity or low-affinity component in the absence of inhibitors, respectively. Kinetic parameters for NT were consistent with those previously determined with human liver microsomes. ${ }^{12)}$ Contributions of CYP2D6 or CYP3A4 to AT E-10-hydroxylation calculated from the obtained kinetic parameters were also in reasonably good agreement with those calculated based on the results of previous experiments using

Table 1. Values of Inhibitory Constant $\left(K_{\mathrm{i}}\right)$ of Terbinafine, Paroxetine and Quinidine for Dextromethorphan $O$-Demethylation $(\mu \mathrm{M})$

\begin{tabular}{lcc}
\hline \hline & \multicolumn{2}{c}{$K_{\mathrm{i}}(\mu \mathrm{M})$} \\
\cline { 2 - 3 } & $\begin{array}{c}\text { With preincubation } \\
\text { value } \pm \text { error }\end{array}$ & $\begin{array}{c}\text { Without preincubation } \\
\text { value } \pm \text { error }\end{array}$ \\
\hline Terbinafine & $0.0389 \pm 0.0164$ & $0.0404 \pm 0.0189$ \\
Paroxetine & $0.143 \pm 0.059^{*}$ & $0.503 \pm 0.148$ \\
Quinidine & $0.0636 \pm 0.0189$ & $0.0882 \pm 0.0254$ \\
\hline
\end{tabular}

$* p<0.05$ (vs. without preincubation). heterologously expressed CYP isoforms. ${ }^{13)}$

Inhibitory Effects of TER for $E$-10-Hydroxylation of AT and NT The Lineweaver-Burk plot indicated that TER competitively inhibits $E$-10-hydroxylation of AT and NT in the presence of itraconazole (Fig. 4). The E-10-hydroxylation activity of AT or NT was reduced dependently upon TER concentration both in the presence and absence of itraconazole (Fig. 5). The values of inhibitory constant $\left(K_{\mathrm{i}}\right)$ of TER for $E$-10-hydroxylation of AT or NT, based on competitive

Table 2. Kinetic Parameters of AT and NT E-10-Hydroxylation by Human Liver Microsomes

\begin{tabular}{ccc}
\hline \hline & Parameter & Value \pm error \\
\hline Amitriptyline & $V_{\max 1}{ }^{a}$ & $36.3 \pm 0.9$ \\
& $K_{\mathrm{m} 1}{ }^{b)}$ & $8.72 \pm 0.74$ \\
$V_{\max 2}{ }^{a}$ & $85.0 \pm 3.1$ \\
& $K_{\mathrm{m} 2}{ }^{b)}$ & $51.1 \pm 3.9$ \\
Nortriptyline & $V_{\max 1}{ }^{a}$ & $32.4 \pm 1.9$ \\
& $K_{\mathrm{m} 1}{ }^{b)}$ & $3.49 \pm 0.83$ \\
& $V_{\max 2}{ }^{a}$ & $52.6 \pm 7.4$ \\
& $K_{\mathrm{m} 2}{ }^{b)}$ & $45.4 \pm 14.0$ \\
\hline
\end{tabular}

a) In pmoles per minute per mg protein. $b$ ) In $\mu \mathrm{M}$. $V_{\max }$ and $K_{\mathrm{m}}$ represent the maximum metabolic velocity and the Michaelis-Menten constant, respectively.
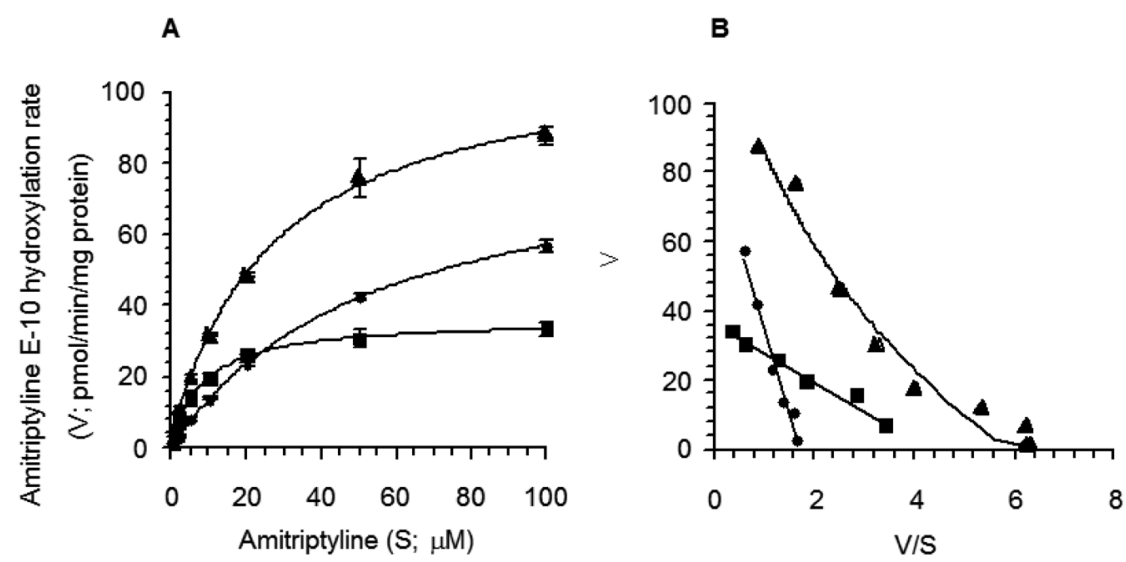

C

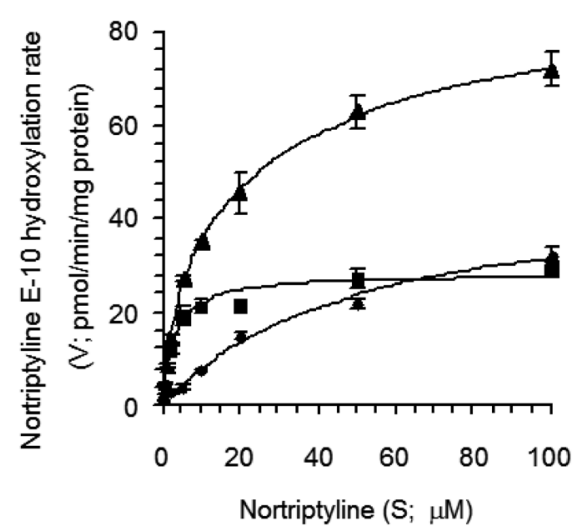

D

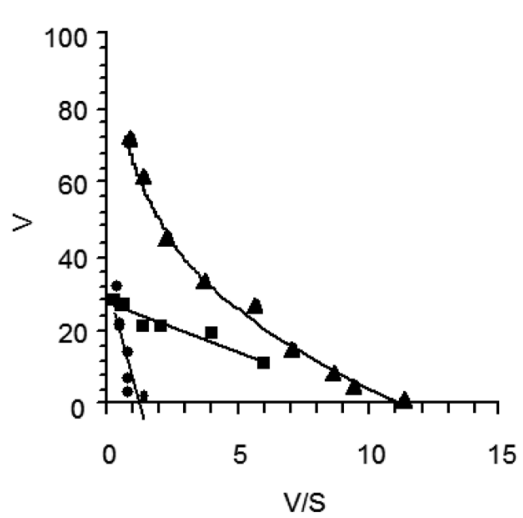

Fig. 3. AT or NT E-10-Hydroxylation by Human Liver Microsomes

Each point represents the mean \pm S.E. $(n=3)$, and the lines are calculated curves based on Eqs. 3-5. Triangles, squares and circles represent data in the absence of inhibitor, in the presence of itraconazole $(1 \mu \mathrm{M})$ and in the presence of quinidine $(5 \mu \mathrm{M})$, respectively. A, B: AT $E$ - 10 -hydroxylation rate, C, D: NT $E$-10-hydroxylation rate. Panels A and C show primary plots (reaction rate $v s$. substrate concentration). Panels B and D are Eadie-Hofstee transformations of the data in panels A and C. Incubation time was $20 \mathrm{~min}$. Both AT E-10-hydroxylation and NT E-10-hydroxylation show biphasic kinetics in the absence of inhibitor, and show selective loss of the low- and highaffinity components in the presence of itaconazole and quinidine, respectively. 


\section{(A) Amitriptyline}

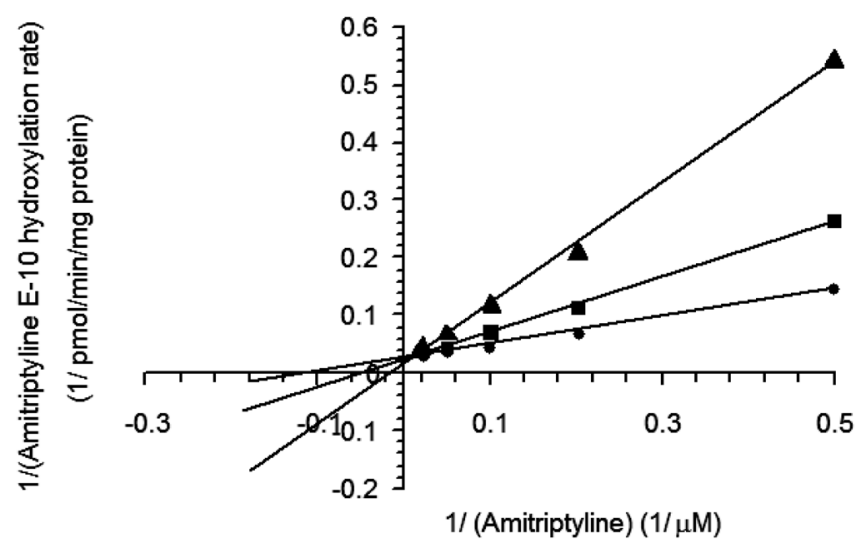

(B) Nortriptyline

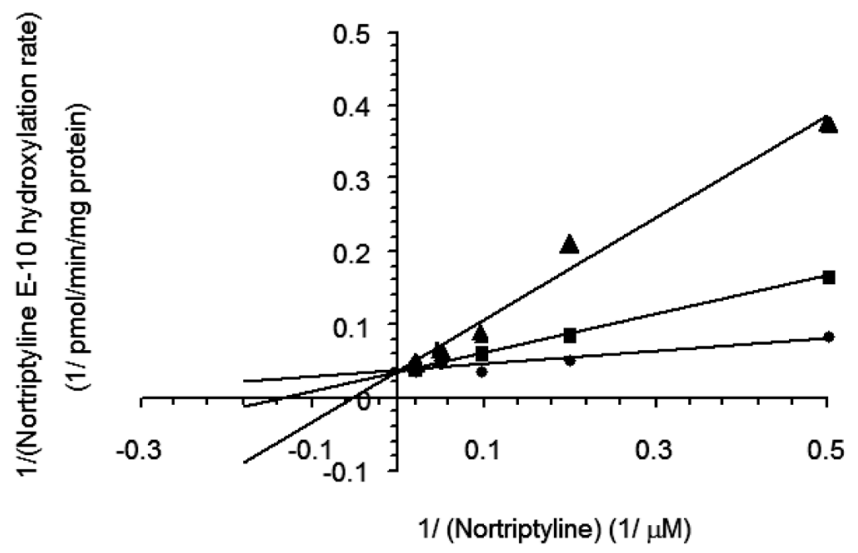

Fig. 4. Lineweaver-Burk Plots for Inhibition of AT or NT E-10-Hydroxylation by TER in Human Liver Microsomes in Vitro

Panels A and B show AT and NT E-10-hydroxylation rates in the presence of TER, respectively. Each point represents the mean $(n=3)$, and the lines are fitted functions. Circles, squares, triangles represent data from experiments performed in the presence of TER $0,0.1,0.5 \mu \mathrm{M}$, respectively. Incubation was performed in the presence of itraconazole $(1 \mu \mathrm{M})$ for $20 \mathrm{~min}$.

inhibition, were calculated to be $233 \pm 26 \mathrm{~nm}$ and $207 \pm 45 \mathrm{~nm}$, respectively.

Unbound Fraction of TER in Human Liver Microsomes and Calculation of Unbound Inhibitory Constant of TER The unbound fraction of TER in human liver microsomes was concentration-dependent (data not shown). The values of unbound $K_{\mathrm{i}}$ of TER for $E$-10-hydroxylation of AT or NT were calculated to be $13.7 \pm 1.1 \mathrm{~nm}$ and $12.4 \pm 2.5 \mathrm{~nm}$, respectively.

Pharmacokinetic Parameters Table 3 shows the pharmacokinetic parameters of AT, NT and TER obtained by fitting the time profile after single-dose administration to the 2-compartment model. However, the time profile of TER plasma concentration after multiple-dose administration was better described by a 3-compartment model (Fig. 6, Table 4). The reason for this difference is that the slow elimination phase (the gamma elimination phase) made no detectable contribution after a single dose of TER, and so the observed plasma concentration of TER after a single dose was better fitted to the 2-compartment model. This is the reason why different compartment models were used for single and multiple-dose administrations of TER. Of course, the time profile after
(A) Amitriptyline

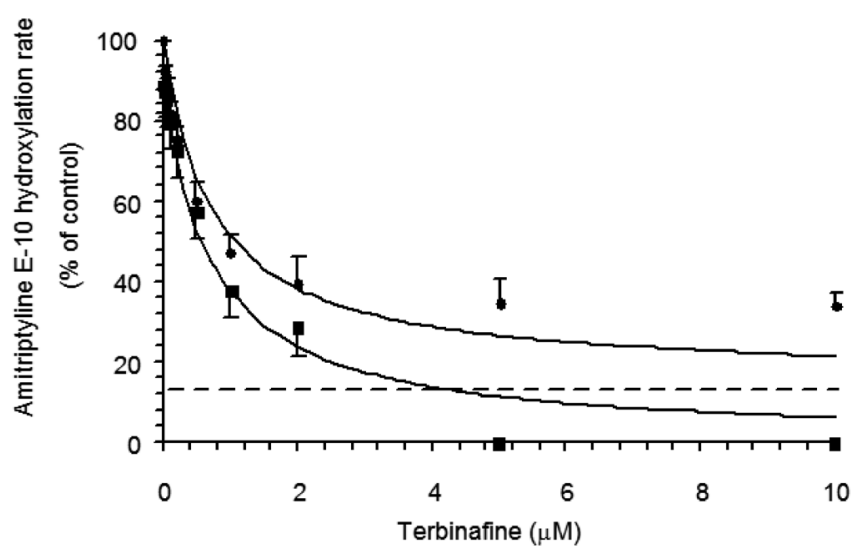

(B) Nortriptyline

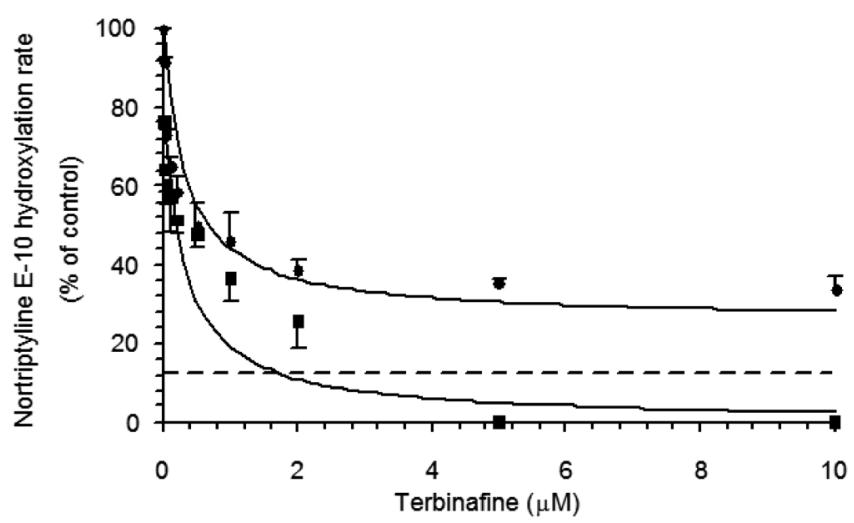

Fig. 5. Inhibition of AT or NT E-10-Hydroxylation by TER in Human Liver Microsomes in Vitro

AT (A) and NT (B) E-10-hydroxylation rates in the presence of TER are expressed as percentages of that in the absence of inhibitor (13.3 \pm 1.0 (A), 18.0 \pm 2.5 (B) $\mathrm{pmol} / \mathrm{min} / \mathrm{mg} /$ protein). Each point represents the mean \pm S.E. $(n=3)$, and solid lines are calculated curves based on Eqs. 6, 7. Squares and circles represent data from experiments performed in the presence or absence of itaconazole $(1 \mu \mathrm{M})$, respectively. Dashed lines represent quantification limits of $E$-10-hydroxylated AT and $E$-10-hydroxylated NT. In the presence of 5 or $10 \mu \mathrm{M}$ TER and $1 \mu \mathrm{M}$ itaconazole, production of $E$-10-hydroxylated AT or $E$-10-hydroxylated NT was under the quantification limit. Initial concentration of AT or NT was $2 \mu \mathrm{m}$, and the incubation time was $20 \mathrm{~min}$.

Table 3. Pharmacokinetic Parameters of Single-Dose Amitriptyline, Nortriptyline and Terbinafine

\begin{tabular}{cccc}
\hline \hline & Parameter & Unit & Value \pm error \\
\hline Amitriptyline $^{1)}$ & $k_{\mathrm{a}, \mathrm{a}}$ & $(/ \mathrm{h})$ & $0.204 \pm 0.092$ \\
& $V_{\mathrm{a}}$ & $(\mathrm{L})$ & 1264 \\
& $F_{\mathrm{a}}$ & - & 0.516 \\
& $k_{\mathrm{e}, \mathrm{a}}$ & $(/ \mathrm{h})$ & $0.0340 \pm 0.0038$ \\
Nortriptyline $^{2)}$ & $k_{\mathrm{a}, \mathrm{n}}$ & $(/ \mathrm{h})$ & $0.239 \pm 0.0598$ \\
& $V_{\mathrm{n}}$ & $(\mathrm{L})$ & 616 \\
& $F_{\mathrm{n}}$ & - & 0.664 \\
Terbinafine $^{3)}$ & $k_{\mathrm{e}, \mathrm{n}}$ & $(/ \mathrm{h})$ & $0.0286 \pm 0.0064$ \\
& $k_{\mathrm{a}, \mathrm{t}}$ & $(/ \mathrm{h})$ & $2.92 \pm 0.46$ \\
& $V_{\mathrm{t}} F_{\mathrm{t}}$ & $(\mathrm{L})$ & 182 \\
& $\alpha$ & $(/ \mathrm{h})$ & $0.512 \pm 0.031$ \\
& $\beta$ & $(/ \mathrm{h})$ & $0.0233 \pm 0.0033$ \\
& $k_{21}$ & $(/ \mathrm{h})$ & 0.0372 \\
\hline
\end{tabular}

$k_{\mathrm{a}}$ : absorption rate constant; $V$ : distribution volume; $F$ : bioavailability; $k_{\mathrm{e}}$ elimination rate constant; $V / F$ : apparent distribution volume of central compartment; $\alpha$ : $\alpha$-phase elimination rate constant; $\beta$ : $\beta$-phase elimination rate constant; $k_{21}$ : equilibrium constant between central and peripheral compartments. 1) ref. 23), 2) ref. 24), 3) ref. 26). 


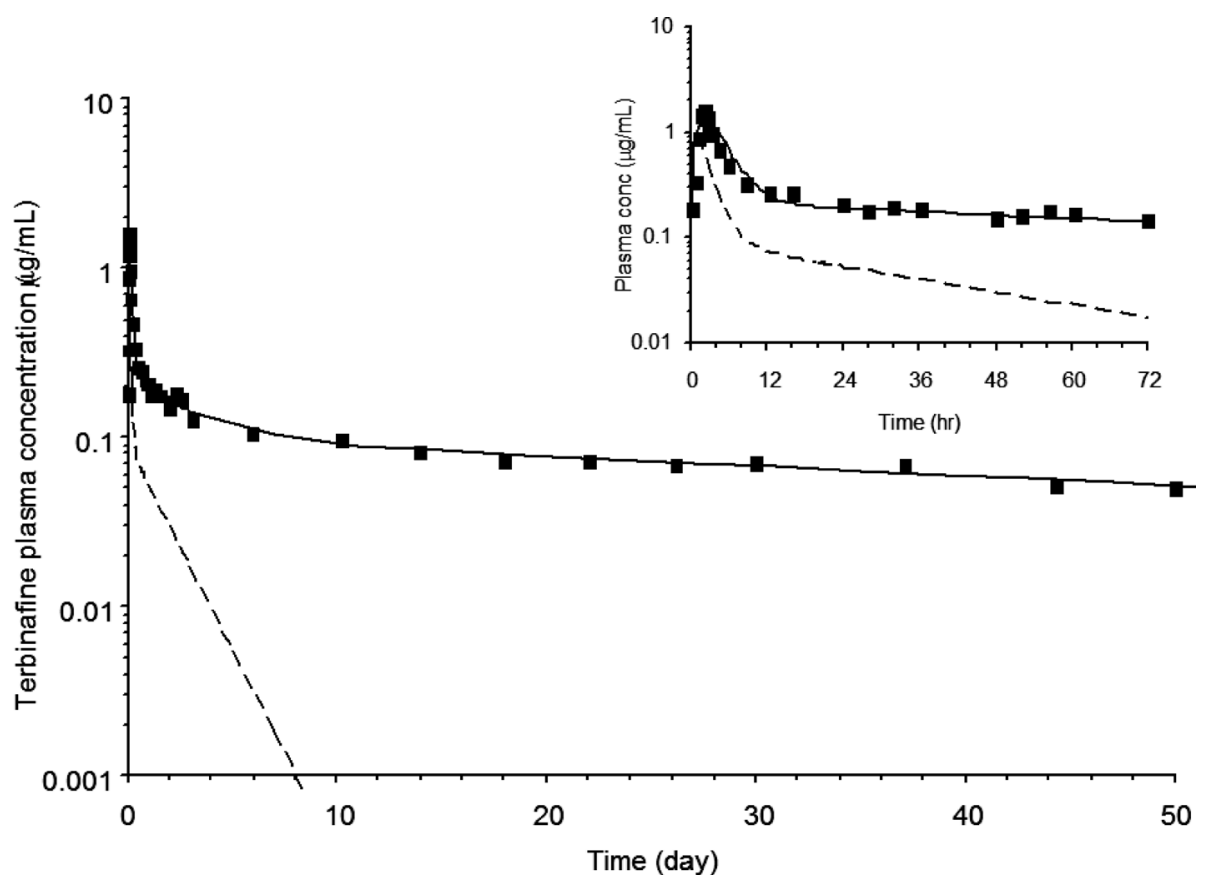

Fig. 6. Multiple-Dose Pharmacokinetics of TER

Symbols represent the observed plasma concentration-time data after repeated administration of $250 \mathrm{mg} / \mathrm{d}$ TER for $28 \mathrm{~d}$, from ref. 14 ). Day 0 is when TER was stopped. Solid lines and dashed lines are calculated curves based on the 3 - and the 2 -compartment models, respectively. The inset shows the initial portions of lines to time $72 \mathrm{~h}$. The 3-compartment model, but not the 2-compartment model, can describe the multiple-dose pharmacokinetics of TER.

Table 4. Pharmacokinetic Parameters of Multiple-Dose Terbinafine ${ }^{1)}$

\begin{tabular}{lcc}
\hline \hline Parameter & Unit & Value \pm error \\
\hline$k_{\mathrm{a}, \mathrm{t}}$ & $(/ \mathrm{h})$ & $0.745 \pm 0.752$ \\
$V_{\mathrm{t}} / F_{\mathrm{t}}$ & $(\mathrm{L})$ & 36.6 \\
$\alpha$ & $(/ \mathrm{h})$ & $0.508 \pm 0.481$ \\
$\beta$ & $(/ \mathrm{h})$ & $0.0188 \pm 0.086$ \\
$\gamma$ & $(/ \mathrm{h})$ & $0.000561 \pm 0.000197$ \\
$k_{21}$ & $(/ \mathrm{h})$ & 0.0219 \\
$k_{31}$ & $(/ \mathrm{h})$ & 0.000834 \\
\hline
\end{tabular}

$k_{\text {a: }}$ absorption rate constant; $V / F$ : apparent distribution volume of central compartment; $\alpha$ : $\alpha$-phase elimination rate constant; $\beta: \beta$-phase elimination rate constant; $\gamma$ : $\gamma$-phase elimination rate constant; $k_{21} k_{31}$ : equilibrium constants between central and peripheral compartments. 1) ref. 14).

single administration could also be simulated using the 3-compartment model and the obtained PK parameters (data not shown).

Model Analysis Table 5 shows drug-drug interaction parameters obtained from model analysis. The developed model could adequately explain the observed time profile of the plasma concentration of AT or NT in each case (Fig. 7).

Prediction of NT Plasma Concentration When NT Is Concomitantly Administered with TER Figure 8 shows the predicted time profile of NT plasma concentration for the case of concomitant administration of NT and TER. Nortriptyline plasma concentration exceeded $200 \mathrm{ng} / \mathrm{mL}$, the level above which NT exerts toxicity, within 1 week. Moreover, $50 \mathrm{~d}$ after cessation of TER, the increased NT plasma concentration had still not returned to baseline when the NT dosage was continued at $75 \mathrm{mg} / \mathrm{d}$. However, when NT was reduced less than $50 \mathrm{mg} / \mathrm{d}$, the NT plasma concentration declined.

Prediction of the Duration of TER/NT Interaction To predict the duration of TER/NT interaction, it was assumed
Table 5. Drug-Drug Interaction Parameters of TER and AT, NT

\begin{tabular}{cccc}
\hline \hline & Parameter & Unit & Value \pm error \\
\hline Common & $K_{\mathrm{P}}$ & - & $67.2 \pm 14.4$ \\
& $r_{\mathrm{n}}$ & - & $0.633 \pm 0.052$ \\
& $f_{\mathrm{u}}^{1)}$ & - & 0.004 \\
Case A $^{2)}$ & $k_{\mathrm{e}, \mathrm{a}}$ & $(/ \mathrm{h})$ & 0.0178 \\
& $k_{\mathrm{e}, \mathrm{n}}$ & $(/ \mathrm{h})$ & 0.0277 \\
& $r_{\mathrm{a}}$ & - & $0.713 \pm 0.035$ \\
Case B $^{3)}$ & $k_{\mathrm{e}, \mathrm{n}}$ & $(/ \mathrm{h})$ & $0.0263 \pm 0.0028$ \\
Case C $^{4)}$ & $k_{\mathrm{e}, \mathrm{n}}$ & $(/ \mathrm{h})$ & $0.0197 \pm 0.0017$ \\
\hline
\end{tabular}

$K_{\mathrm{P}}$ : TER liver-to-plasma unbound concentration ratio; $r$ : fractional contribution of CYP2D6 to overall clearance of AT or NT; $f_{\mathrm{u}}$ : TER unbound fraction in plasma; $k_{\mathrm{e}}$ : elimination rate constant of AT or NT. 1) ref. 18), 2) ref. 8), 3) ref. 9), 4) ref. 10).

that NT is started after cessation of TER therapy at 125 or $250 \mathrm{mg} / \mathrm{d}$. Regardless of TER dosage, the inhibitory effect of TER increased as the dosing period was increased, and it took more than $300 \mathrm{~d}$ after cessation of TER for the NT AUC to return to baseline (Fig. 9).

\section{DISCUSSION}

We found that TER $(1-10 \mu \mathrm{M})$ did not inhibit CYP3A4 activity. This finding is consistent with a report that TER did not influence the metabolism of testosterone in vitro ${ }^{27)}$ or that of midazolam in vivo. ${ }^{28)}$ Thus, the inhibitory effects of TER on metabolism of AT and NT are mediated exclusively by drug interaction at CYP2D6. In the presence of itraconazole, a selective CYP3A4 inhibitor, TER competitively inhibited the $E$-10-hydroxylation of AT and NT. In addition, the $K_{\mathrm{i}}$ values of TER against the $E$-10-hydroxylation activities of AT and NT were nearly equal. This study has also confirmed that the CYP2D6-inhibitory effect of TER is not influenced by 

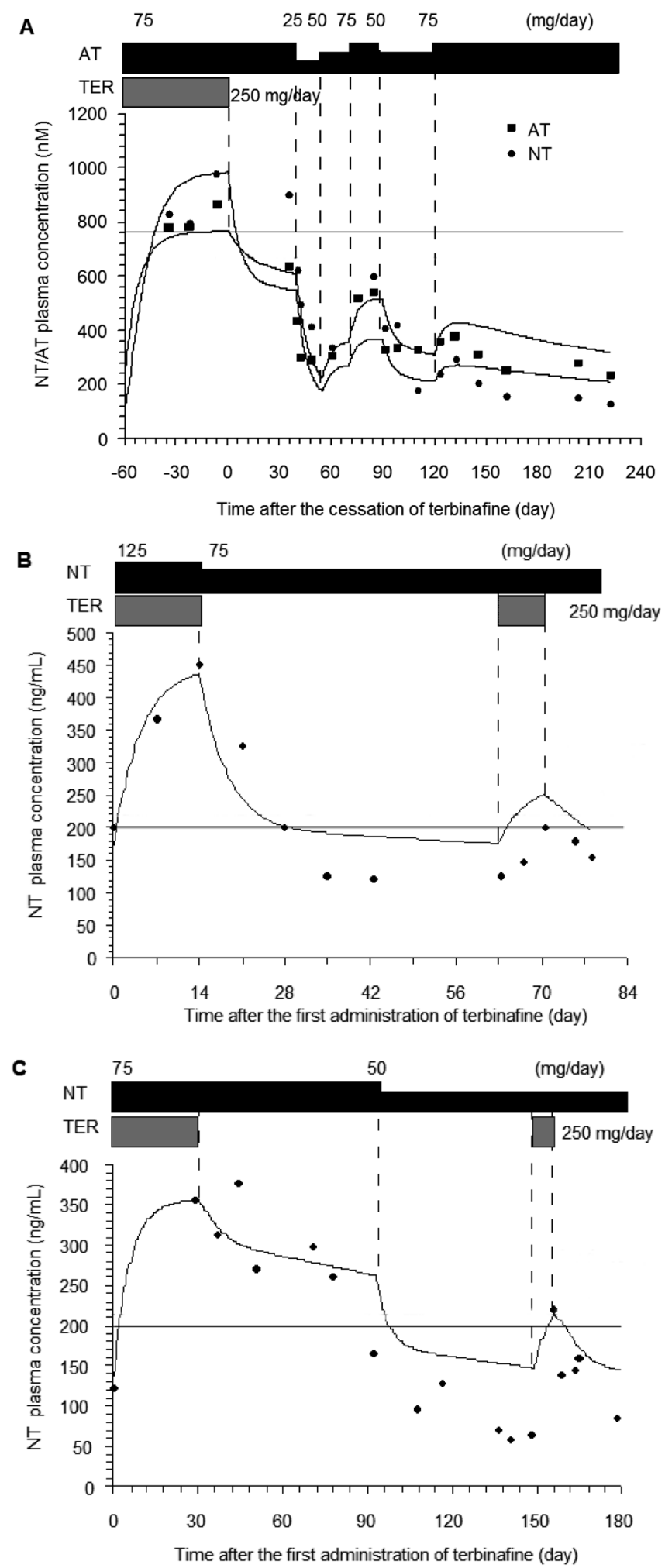

Fig. 7. Analysis of Pharmacokinetics of AT and NT (A) or NT (B, C) Concomitantly Used with TER

Symbols represent the observed plasma concentration-time data of AT (squares) and NT (circles) from case reports. Lines are calculated curves based on the drugdrug interaction model of TER and AT, NT (Fig. 1). A: ref. 8), B: ref. 9), C: ref. 10).

pre-incubation, as previously reported by Akiyoshi et al. ${ }^{17)}$ Therefore, it appears that the long persistence of TER interactions is not due to irreversibility, but rather is due to reversible competitive inhibition of CYP2D6 by TER.

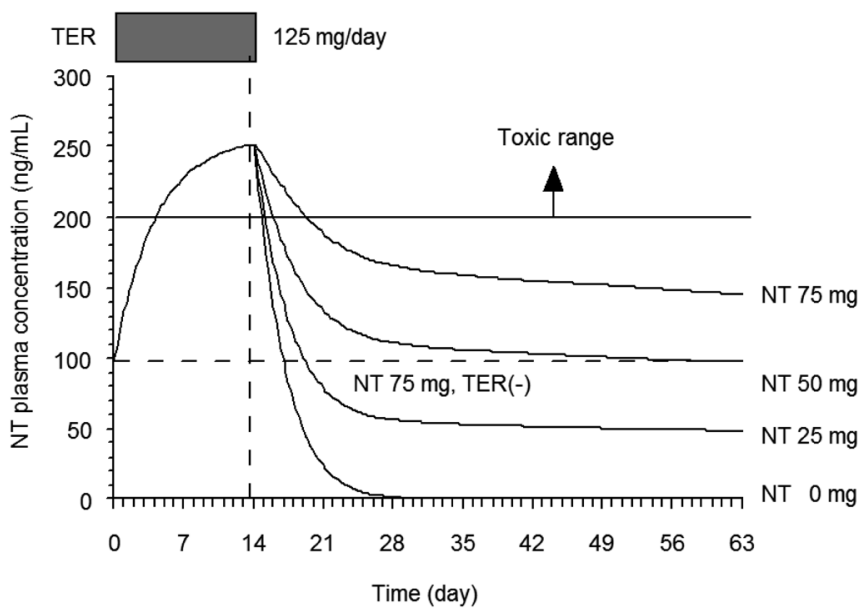

Fig. 8. Simulated Profiles of NT Plasma Concentration after Administration of NT Alone or Concomitantly with TER

Solid lines represent the simulated NT plasma concentration based in the drug-drug interaction model of TER and NT (Fig. 1). Nortriptyline $75 \mathrm{mg} / \mathrm{d}$ is administere in combination with $125 \mathrm{mg} / \mathrm{d}$ TER from day 0 to day 14 , then TER is stopped and the NT dosage is altered to the range from 0 to $75 \mathrm{mg} / \mathrm{d}$. Dashed line represents the NT plasma concentration after $75 \mathrm{mg} / \mathrm{d}$ NT is administered alone.

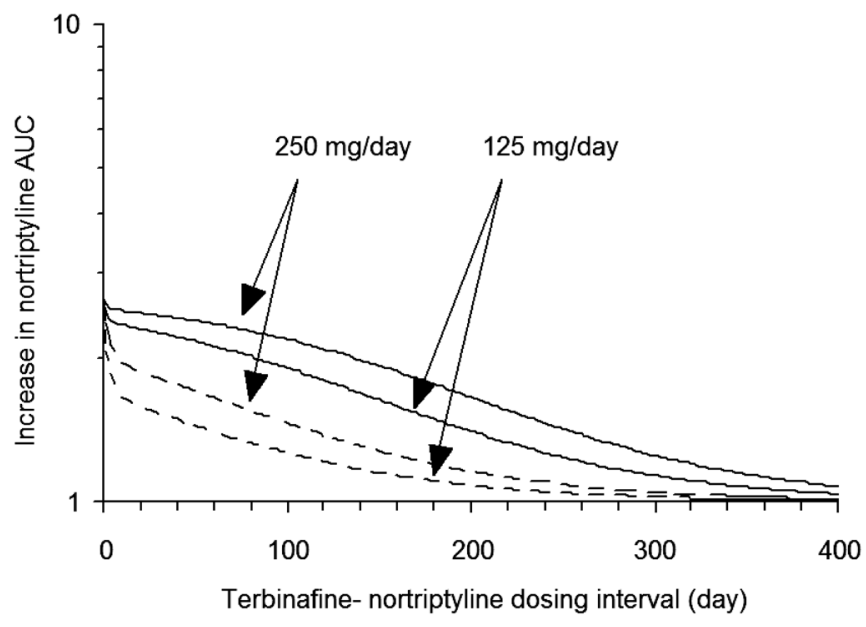

Fig. 9. Simulated Increase in NT $A U C$ after TER Therapy

Lines represent increase of the $A U C$ of NT when NT is administered after cessation of TER. Solid and dashed lines represent the TER dosing period of infinity (long enough for the TER plasma concentration to reach the steady state) and $14 \mathrm{~d}$, respectively. Terbinafine dosage is 125 or $250 \mathrm{mg} / \mathrm{d}$.

To date, there has been no report on the binding ratio of TER to human hepatic microsomes. The present results indicate that the $K_{\mathrm{i}}$ values of TER against $E$-10-hydroxylation of AT and NT were approximately 17 times larger when the influence of non-specific binding to human hepatic microsomes was not considered, compared with the values obtained by taking this into account. Hence, it was suggested that the in vivo metabolic inhibitory effect of TER predicted from in vitro data might be underestimated if the ratio of bound/nonbound TER is not taken into account. However, the result of quantitative prediction in the present model analysis is not affected by the $K_{\mathrm{i}}$ value, because $K_{\mathrm{P}}$ is estimated as the adjusted value. It was also found that TER exhibited very high affinity for CYP2D6, judging from the $K_{\mathrm{i}}$ ' values of non-bound TER. Equilibrium dialysis revealed a linear relationship between TER concentration in the sample and the concentration of 
initially added TER; however, the ratio of the TER concentration in the sample to the TER concentration upon initial addition of non-bound TER alone decreased. On the other hand, the TER recovery ratio and the ratio of non-bound TER to human hepatic microsomes decreased with increasing TER concentration, suggesting that non-specific adsorption of TER increases with increasing concentration. Although the mechanism involved remains unknown, there may be an association with the very high affinity of TER for plasma proteins, such that the protein binding of TER does not saturate up to $5.4 \mu \mathrm{M}$, which is in the range of clinical plasma concentrations. ${ }^{29)}$ In addition, Kato et al. previously indicated that the discrepancy between in vitro and in vivo $K_{\mathrm{i}}$ values became larger with increase of lipophilicity. ${ }^{30)}$ The ratios of non-bound TER to human hepatic microsomes obtained in the present study, 0.02 to 0.06 , are considered reasonable in view of the very high liposolubility of TER. ${ }^{31)}$

From the time course of plasma TER concentration following oral administration of TER for 28 consecutive days, the plasma non-bound TER concentration at Week 3 to 4 after discontinuation of TER was $0.855 \mathrm{~nm}$, and the liver concentration of the non-bound TER was $57.46 \mathrm{~nm}$, which is approximately 4 times higher than the $K_{\mathrm{i}}$ ' value of non-bound TER obtained in the present study. It can be predicted, therefore, that TER would still exhibit potent inhibitory activity even 3 to 4 weeks after its discontinuation, confirming the long persistence of the CYP2D6-inhibitory effect of TER, despite its reversibility.

Analysis using a compartment model suggested three elimination phases in the disposition of TER in oral administration on consecutive days, with a very long half-life of $51 \mathrm{~d}$ in the third elimination phase. However, the disposition of TER after single oral administration was better expressed by a 2-compartment model than by a 3-compartment model, because the gamma elimination phase made no detectable contribution in the case of single-dose administration of TER, i.e., it was negligible in the case of short-term treatment. TER is highly liposoluble, and the concentrations in sebum and epidermal stratum corneum remain high even at $50 \mathrm{~d}$ after discontinuation of TER. ${ }^{32,33)}$ Hence, a very long time is taken for systemically accumulated TER to return to the plasma, and this is believed to be the origin of the third elimination phase of TER.

While no study has so far been reported on the liver/plasma unbound concentration ratio $\left(K_{\mathrm{P}}\right)$ of TER in vivo, we estimated the $K_{\mathrm{P}}$ value of TER to be 67.2 by fitting to the drug-drug interaction model (Table 5); this result suggests for the first time that TER might be concentrated in human liver. There are three metabolites of TER: carboxyl form, demethylated form, and hydroxide. Their dispositions are characterized by very long elimination half-lives, as is the case with TER. ${ }^{34)}$ Therefore, should these metabolites possess CYP2D6-inhibitory activity, the apparent $K_{\mathrm{P}}$ value might be higher than the actual level; further investigation is needed to resolve this issue.

The interaction model developed in the present study mostly well simulated the time courses of plasma AT and NT concentrations during concomitant use of TER and AT or NT (Fig. 7). However, there was a slight overestimation of NT plasma concentration at the time of re-administration of TER (Fig. 7B). One possible explanation of the discrepancy between the measured and predicted values would be that the marked rise in NT plasma level at the time of the first concomitant use of TER resulted in a nonlinear change of metabolism. It is a limitation of this study that the model analysis was conducted based on limited data collected from three case reports. Addition of further clinical data on the interaction of TER with other CYP2D6 metabolic drugs such as desipramine should be useful to increase the validity of the model analysis in the future.

TER-NT interaction at the dose of TER recommended in Japan (125 mg given once daily) was evaluated using this model, and it was predicted that adverse reactions to NT would be induced with concomitant use of the two drugs, as was the case with a TER dose of $250 \mathrm{mg}$ given once daily, ${ }^{10}$ ) and also inhibition of NT metabolism by TER would persist for 4 weeks or longer after discontinuation of TER. Therefore, concomitant use of TER and NT should be avoided whenever possible. In the event of erroneous concomitant use of the two drugs, the model suggested that not only TER discontinuation, but also NT dose reduction should be implemented at the same time to quickly restore plasma NT concentration to the level obtained without the concomitant use of TER. The duration of interaction of TER was estimated to be as long as 300 to $400 \mathrm{~d}$, irrespective of the dose of TER. For this reason, it would be important to consider the patient's history of TER medication before starting the use of NT in clinical settings.

Great caution should also be exercised when using TER concomitantly with other CYP2D6 substrate drugs. For example, a clinical study involving concomitant use of TER and the antidepressant desipramine found increased plasma desipramine concentrations when desipramine was given at a 4-week interval after oral administration of TER for 21 consecutive days, ${ }^{3)}$ and another clinical study involving concomitant use of TER and the antitussive dextromethorphan showed that a period of more than 3 months was required for the dextromethorphan/dextrorphan metabolism ratio to return to the level observed in the absence of concomitant TER after oral administration of TER for 14 consecutive days. ${ }^{5}$ These findings may be viewed as representing interactions arising from the long persistence of the CYP2D6-inhibitory effect of TER. It is important to note that CYP2D6 substrate drugs include many in wide clinical use, including circulatory drugs and beta blockers. Indeed, one case was reported in which the plasma concentration of the anti-arrhythmic perhexiline rose remarkably during concomitant administration with TER, and at least 3 months was required for restoration to a baseline $\mathrm{OH}-$ perhexiline/perhexiline ratio after discontinuation of TER. ${ }^{35)}$ We believe the model developed in the present study would also be applicable to evaluation of interactions of other CYP2D6 substrate drugs with TER.

In the present study, we were able to quantitatively evaluate the inhibitory effects of TER on AT and NT metabolism, showing that CYP2D6 inhibition by TER is reversible, but persists for a long time. Such behavior is rare among drugs exhibiting reversible competitive inhibition. Our model should be useful in managing interactions between TER and CYP2D6 substrate drugs, which are otherwise difficult to predict due to their time dependency.

Conflict of Interest The authors declared no conflict of interest. 


\section{REFERENCES}

1) Teitelbaum ML, Pearson VE. Imipramine toxicity and terbinafine. Am. J. Psychiatry, 158, 2086 (2001)

2) O’Reardon JP, Hetznecker JM, Rynn MA, Baldassano CF, Szuba MP. Desipramine toxicity with terbinafine. Am. J. Psychiatry, 159, 492 (2002).

3) Madani S, Barilla D, Cramer J, Wang Y, Paul C. Effect of terbinafine on the pharmacokinetics and pharmacodynamics of desipramine in healthy volunteers identified as cytochrome P450 2D6 (CYP2D6) extensive metabolizers. J. Clin. Pharmacol., 42, 1211-1218 (2002).

4) Yasui-Furukori $N$, Saito M, Inoue $Y$, Niioka T, Sato $Y$, Tsuchimine $\mathrm{S}$, Kaneko S. Terbinafine increases the plasma concentration of paroxetine after a single oral administration of paroxetine in healthy subjects. Eur. J. Clin. Pharmacol., 63, 51-56 (2007).

5) Abdel-Rahman SM, Gotschall RR, Kauffman RE, Leeder JS, Kearns GL. Investigation of terbinafine as a CYP2D6 inhibitor in vivo. Clin. Pharmacol. Ther., 65, 465-472 (1999).

6) Cai WM, Chen B, Ling SS, Zhang YD. Terbinafine-associated inhibition of dextromethorphan metabolism in Chinese subjects. Br.J. Clin. Pharmacol., 51, 107-108 (2001).

7) Park YM. Prolonged drug-drug interaction between terbinafine and perphenazine. Psychiatry Investig., 9, 422-424 (2012).

8) Castberg I, Helle J, Aamo TO. Prolonged pharmacokinetic drug interaction between terbinafine and amitriptyline. Ther. Drug Monit., 27, 680-682 (2005).

9) van der Kuy P-HM, Hooymans PM, Verkaaik AJB. Nortriptyline intoxication induced by terbinafine. BMJ, 316, 441 (1998).

10) van der Kuy P-HM, van den Heuvel HA, Kempen RW, Vanmolkot LML. Pharmacokinetic interaction between nortriptyline and terbinafine. Ann. Pharmacother., 36, 1712-1714 (2002).

11) Breyer-Pfaff U. The metabolic fate of amitriptyline, nortriptyline and amitriptylinoxide in man. Drug Metab. Rev., 36, 723-746 (2004).

12) Venkatakrishnan K, von Moltke LL, Greenblatt DJ. Nortriptyline $E$ 10-hydroxylation in vitro is mediated by human CYP2D6 (high affinity) and CYP3A4 (low affinity): Implications for interactions with enzyme-inducing drugs. J. Clin. Pharmacol., 39, 567-577 (1999).

13) Venkatakrishnan K, von Moltke LL, Greenblatt DJ. Application of the relative activity factor approach in scaling from heterologousy expressed cytochromes P450 to human liver microsomes: Studies on amitriptyline as a model substrate. J. Pharmacol. Exp. Ther., 297, 326-337 (2001).

14) Kovarik JM, Mueller EA, Zehender H, Denouel J, Caplain H, Millerioux L. Multiple-dose pharmacokinetics and distribution in tissue of terbinafine and metabolites. Antimicrob. Agents Chemother., 39, 2738-2741 (1995).

15) Vickers AE, Sinclair JR, Zollinger M, Heitz F, Glanzel U, Johanson L, Fischer V. Multiple cytochrome P-450s involved in the metabolism of terbinafine suggest a limited potential for drug-drug interactions. Drug Metab. Dispos., 27, 1029-1038 (1999).

16) Abdel-Rahman SM, Marcucci K, Boge T, Gotschall RR, Kearns GL, Leeder JS. Potent inhibition of cytochrome P-450 2D6-mediated dextromethorphan $O$-demethylation by terbinafine. Drug Metab. Dispos., 27, 770-775 (1999).

17) Akiyoshi $T$, Ishiuchi $M$, Imaoka $A$, Ohtani $H$. Variation in the inhibitory potency of terbinafine among genetic variants of CYP2D6. Drug Metab. Pharmacokinet., 30, 321-324 (2015).
18) Interview form of Lamisil $^{\circledR}$ tablets $125 \mathrm{mg}$. Mitsubishi Tanabe Pharma, Version 11. 2016.10.

19) Tod M, Goutelle S, Clavel-Grabit F, Nicolas G, Charpiat B. Quantitative prediction of cytochrome P450 (CYP) 2D6-mediated drug interactions. Clin. Pharmacokinet., 50, 519-530 (2011).

20) Vandel B, Sandoz M, Vandel S, Allers G, Volmat R. Biotransformation of amitriptyline in depressive patients: urinary excretion of seven metabolites. Eur. J. Clin. Pharmacol., 22, 239-245 (1982).

21) Alexanderson B, Borga O. Urinary excretion of nortriptyline and five of its metabolites in man after single and multiple oral doses. Eur. J. Clin. Pharmacol., 5, 174-180 (1973).

22) Furlanut M, Benetello P, Spina E. Pharmacokinetic optimisation of tricyclic antidepressant therapy. Clin. Pharmacokinet., 24, 301-318 (1993).

23) Wong SL, Cavanaugh J, Shi H, Awni WM, Granneman GR. Awni and G. Richard Granneman. Effects of divalproex sodium on amitriptyline and nortriptyline pharmacokinetics. Clin. Pharmacol. Ther., 60, 48-53 (1996).

24) Yue QY, Zhong ZH, Tybring G, Dalen P, Dahl ML, Bertilsson L, Sjoqvist F. Pharmacokinetics of nortriptyline and its 10-hydroxy metabolite in Chinese subjects of different CYP2D6 genotypes. Clin. Pharmacol. Ther., 64, 384-390 (1998).

25) Davies B, Morris T. Physiological parameters in laboratory animals and humans. Pharm. Res., 10, 1093-1095 (1993).

26) Kovarik JM, Kirkesseli S, Humbert H, Grass P, Kutz K. Dose-proportional pharmacokinetics of terbinafine and its $N$-demethylated metabolite in healthy volunteers. Br. J. Dermatol., 126 (Suppl. 39), $8-13(1992)$

27) Obach RS, Walsky RL, Venkatakrishnan K, Gaman EA, Houston JB, Tremaine LM. The utility of in vitro cytochrome P450 inhibition data in the prediction of drug-drug interactions. J. Pharmacol. Exp. Ther., 316, 336-348 (2006).

28) Ahonen J, Olkkola KT, Neuvonen PJ. Effect of itraconazole and terbinafine on the pharmacokinetics and pharmacodynamics of midazolam in healthy volunteers. Br. J. Clin. Pharmacol., 40, 270-272 (1995).

29) Jensen JC. Pharmacokinetics of lamisil in humans. J. Dermatolog. Treat., 1 (Suppl.), 15-18 (1990).

30) Kato M, Shitara Y, Sato H, Yoshisue K, Hirano M, Ikeda T, Sugiyama Y. The quantitative prediction of CYP-mediated drug interaction by physiologically based pharmacokinetic modeling. Pharm. Res., 25, 1891-1901 (2008).

31) Schafer-Korting M. Pharmacokinetic optimisation of oral antifungal therapy. Clin. Pharmacokinet., 25, 329-341 (1993).

32) Balfour JA, Faulds D. Terbinafine. A review of its pharmacodynamic and pharmacokinetic properties, and therapeutic potential in superficial mycoses. Drugs, 43, 259-284b (1992).

33) Faergemann J, Zehender H, Denouel J, Millerioux L. Levels of terbinafine in plasma, stratum corneum, dermis-epidermis (without stratum corneum), sebum, hair and nails during and after $250 \mathrm{mg}$ terbinafine orally once per day for four weeks. Acta Derm. Venereol., 73, 305-309 (1993).

34) Humbert H, Denouel J, Cabiac MD, Lakhdar H, Sioufi A. Pharmacokinetics of terbinafine and five known metabolites in children, after oral administration. Biopharm. Drug Dispos., 19, 417-423 (1998).

35) Sheikh AR, Westley I, Sallustio B, Horowitz JD, Beltrame JF. Interaction of terbinafine (anti-fungal agent) with perhexiline: a case report. Heart Lung Circ., 23, e149-e151 (2014). 